\title{
CLONAGEM EM SERES HUMANOS? UM BALANÇO PROVISÓRIO DO DEBATE EM TORNO DA ÉTICA JURÍDICA*
}

\author{
Otfried Höffe**
}

RESUMO - No presente artigo, o autor apresenta um balanço do debate em torno da questão da clonagem de seres humanos, apontando os limites argumentativos na discussão sobre a clonagem reprodutiva e a clonagem terapêutica. PALAVRAS-CHAVE - Clonagem reprodutiva. Clonagem terapêutica. Ética.
ABSTRACT - In this study the author offers an evaluation of the debate concerning the topic of cloning of human beings, pointing out to the argumentative limits in the discussion about reproductive cloning and therapeutic cloning. KEY WORDS - Reproductive cloning. Therapeutic cloning. Ethics.

\section{Três erros de argumentação}

A Ética e o Direito não entram em cena apenas como guardas de fronteira e instâncias de veto. Para as Ciências Biológicas, elas justificam, num primeiro momento, espaços de ação. O Direito confere à liberdade de pesquisa a condição de bem jurídico que, como um trunfo, desbanca outros interesses, enquanto direito fundamental. E a ética filosófica reconhece na sede de saber uma forma suprema da razão, na forma exonerada da utilidade até uma segunda espécie de liberdade de pesquisa, isto é, uma sede de saber que não serve a terceiros, mas a si mesma. Conforme se pode observar nos lactentes, ela principia logo depois do nascimento e continua, para quem tem a sorte de Albert Camus, na escola fundamental: "Na classe de Monsieur Germain eles sentiram pela primeira vez que [...] eram objeto do maior respeito: consideravam-nos dignos de descobrir o mundo" - eis o que lemos na autobiografia O primeiro homem. Mas se a pesquisa se coloca a serviço de terceiros, as Ciências Biológicas estão na situação confortável de poderem invocar o mandamento de ajuda interculturalmente reconhecido, que, no caso do médico, até integra o juramento hipocrático. Não é mero acaso que o médico, que

\footnotetext{
Palestra proferida no Instituto Goethe, em Porto Alegre, no evento "Ética e Genética III: Interven* ção genética e dignidade humana". Tradução de Peter Naumann.

Professor da Universidade de Tübingen, Alemanha.
}

\begin{tabular}{|l|l|l|l|l|l|}
\hline VERITAS & Porto Alegre & v. 51 & n. 1 & Março 2006 & p. 84-95 \\
\hline
\end{tabular}


presta ajuda em momentos de evidente necessidade, goza do mais elevado prestígio social, que na Alemanha atinge $72 \%$ e duplica assim o do segundo colocado, do sacerdote (cf. pesquisa de opinião realizada pelo Instituto de Allensbach em 2003). Mas a clonagem em seres humanos coloca em pauta outros bens jusfundamentais, isto é, trunfos concorrentes. Por sua causa, o Direito e a Ética se vêem desafiados enquanto guardiães das fronteiras que sempre fazem parte dos espaços de ação, pois não há legitimação sem limitação. O juramento hipocrático afirma sem meio-termo: primum nil nocere, de qualquer modo não causar dano.

Uma reflexão adequada ao objeto deve evitar três erros. Os dois primeiros pretendem denunciar unilateralmente a necessária "cooperação" entre a Biologia e a Ética; o terceiro desconhece uma condição marginal que em princípio sempre existiu, mas hoje se reveste de especial autoridade. O primeiro erro, o de inferir o dever-ser do ser, é uma ameaça do campo das ciências naturais, manifesta, e.g., onde elas querem traçar a linha de demarcação entre o permitido e o não-permitido a partir de uma compreensão racional da natureza, no caso da Biologia. Nem necessitamos recorrer à Lógica formal para desmascarar essa "falácia biologicista" e ver que as Ciências Biológicas nos transmitem ensinamentos sobre uma realidade admiravelmente complexa, mas não sobre um dever-ser de qualquer natureza. Um olhar mais atento descobre princípios escondidos, assim, e.g., a adaptabilidade do nosso gênero enquanto grandeza normativa a ser atingida. No entanto, sucumbe à falácia de inferir o dever-ser do ser também quem inversamente fundamenta limites da pesquisa com a afirmação de que o ser humano não seria criador, mas criatura. Por um lado, essa referência procede, para uns, por motivos religiosos, para outros, por motivos evolucionistas. Mas como descrição da condição humana, ela não contém nenhum potencial para prescrições. Isso falta também onde se impõe um tabu sobre novas opções com a afirmação de que o homem "não deveria brincar de Deus". Abstraindo do fato de a pesquisa biomédica, com a sua promessa de diagnósticos e terapias de nova espécie, não ser uma brincadeira, mas um fenômeno de seriedade existencial, os conhecimentos e as habilidades científicas aumentaram enormemente. Mais especificamente, os módulos com os quais trabalhamos tornam-se cada vez mais elementares. Para Craig Venter, eles são letras genéticas individuais. Mas como os pesquisadores dependem de orientações prévias, eles continuam separados por um abismo da forma divina da criação ex nihilo. Em contrapartida, são, enquanto seres feitos à imagem de Deus, tanto capazes da criação subdivina, da criação de segunda mão, quanto lhes assiste o direito a ela, no âmbito do Direito e da Ética. E como as criações de segunda mão em regra são imperfeitas, elas nunca chegam a termo, diferentemente da criação originária divina; a pesquisa biomédica também é um processo sem fim previsível.

À falácia contrária, de inferir o ser do dever-ser, sucumbem os moralistas que erigem as suas proibições, sem o conhecimento suficiente dos fatos biológicos. Falam genericamente sobre a clonagem, sem distinguir finalidades e procedimentos distintos, ou consideram a clonagem um procedimento apenas artificial, obra de seres humanos. Em verdade, ela já aparece na natureza, nas plantas, em um 
sentido tão literal que até a expressão "clone: rebento" tem sua origem nelas. Mas animais simples também clonam, e.g., esponjas, pólipos e dáfnias, do mesmo modo que pulgões, os quais, no entanto, preferem multiplicar-se por via sexual, em virtude das desvantagens de cópias com cromossomos idênticos. De qualquer modo, a natureza prefere a multiplicação por via sexual em animais mais complexos, "superiores", por causa do "interesse" genérico pela diversidade.

O terceiro erro bioético infringe o nosso mundo vivido [Lebenswelt] político, que consiste no plano doméstico em uma democracia liberal, pluralista, e no plano global em uma coexistência ainda mais multiforme de visões do mundo e religiões. Nessa situação é vedado transformar princípios com validade particular em princípios genericamente vinculantes, à medida que se parte, e.g., de uma metafísica obsoleta ou de premissas vinculadas a confissões. A Ética filosófica, porém, invoca tão-somente a razão humana universal, experiências humanas igualmente universais e, no âmbito de uma ética aplicada como a Bioética, princípios jurídicos universalmente reconhecidos, como os direitos fundamentais e humanos. ${ }^{1}$

\section{Geração de filhos?}

Onde aparece algo novo, floresce rapidamente um par de gêmeos, ao qual, no entanto, falta a identidade genética: a esperança e o temor. Na Biomedicina, eles foram alimentados durante muito tempo especialmente por partes opostas: a esperança pelos cientistas, o temor por uma esfera pública alarmada. Felizmente essa divisão do trabalho está entrementes superada. Pois onde a pesquisa é realizada sem antolhos, os perigos aparecem quase que de per se. A ovelha Dolly não se caracterizou por uma excessiva vitalidade. Mesmo com relação ao organismo-modelo para os mamíferos, o camundongo, Rudolf Jaenisch relata (2003) que a manipulação dos óvulos só é exitosa em 1 a 4\%. Mesmo nas manipulações bem-sucedidas, muitas dúzias de genes importantes do núcleo celular transferido saem fora de controle. E de acordo com Gerald Schatten (2003), as experiências realizadas com macacos rhesus, conscientemente escolhidos como substitutos do homem, malograram completamente (de acordo com o conhecimento até o momento, isso já era de se esperar!). Nenhum dos 716 óvulos manipulados evoluiu na direção de um embrião, muito menos na de um macaco rhesus acabado. E dentre os 33 embriões gerados, que foram transferidos às fêmeas fecundáveis dos macacos, todos os clones morreram cedo. Supõe a seguinte causa: já nas primeiras divisões de células, os cromossomos não se ordenam corretamente, pois, graças às proteínas importantes, os apparatus fusales se desorganizam, com a conseqüência de que os encaminhamentos genéticos falhos são praticamente inevitáveis. Os pesquisadores resumem: "Com os procedimentos presentes a produção de células-tronco embrionárias com a técnica de transferência do núcleo poderia resultar difícil em primatas não-humanos - e a clonagem reprodutiva um objetivo inalcançável".

1 Uma boa compreensão do debate é oferecida pelo Reader 2003; Forum Diderot 1999; McLaren 2002; também por Council 2002, capítulos 5 e 6 . 
Estaríamos assim presenciando a dissolução da esperança apressada, e com ela também o risco do desemprego da Ética e do Direito enquanto guardiães da fronteira? Entrementes há um consenso avassalador com relação à proibição da clonagem reprodutiva, tanto entre naturalistas quanto também entre os especialistas em Ética e Direito. Jaenisch e Ian Wilmut, o "pai da ovelha Dolly", declararam, em lugar proeminente, na revista Science: "Don’t clone Humans!" No seu relatório sobre Human Cloning and Human Dignity (2001), a Comissão Kass, Conselho de Bioética do Presidente dos EUA, decide por unanimidade proibir rigorosamente, por tempo ilimitado, a clonagem para fins de geração de filhos em seres humanos. Já cinco anos antes, o Parlamento Europeu, e seis semanas depois, uma Comissão francesa, outras seis semanas depois, uma Comissão norte-americana e, em novembro do mesmo ano 1997, a Assembléia Geral das Nações Unidas decidem pela proibição da clonagem humana, parcialmente pela proibição abrangente, parcialmente pela proibição da clonagem reprodutiva (cf. o dossiê extenso de 2003). Apesar disso, o filósofo prefere aprofundar a indagação, pois, se os argumentos não são convincentes, o consenso será fragmentário. De qualquer modo, houve também quem votasse a favor na discussão dos anos 60 e 70 (e.g., Fletcher 1974, criticamente Jonas 1972), aos quais se juntaram há uma década quase duas dúzias de pesquisadores de alto quilate.

Três argumentos para a proibição saltam aos olhos: em primeiro lugar, a clonagem não é apenas imensamente complicada já nos animais superiores, mas, além disso, imensamente arriscada; a maioria dos experimentos termina em abortos ou malformações. Em segundo lugar, no caso dos seres humanos, mesmo os deficientes mais graves possuem o pleno direito à vida. Em terceiro lugar, seria terrivelmente entediante, se todos os seres humanos fossem iguais; afinal de contas, cada qual quer ser um indivíduo inconfundível.

À primeira vista, cada um dos argumentos, mas sobretudo a sua combinação, impulsiona na direção de uma proibição absoluta. À segunda vista, por ocasião da pergunta pelo alcance dos argumentos, remanesce apenas uma proibição relativa. O segundo argumento citado, jurídico e moral, não é passível de controvérsias. Pode acrescer até um ponto de vista juscivilista, que no entanto é controvertido: se a clonagem produz um deficiente, ele tem, por um lado, pleno direito à vida e pode, por outro, entrar, por si ou por meio de um representante, com uma ação de indenização por danos, de modo que o risco correspondente refreia também a vontade de clonar.

Por um lado, podemos aduzir razões biológicas tão boas para o primeiro argumento, a hipótese factual "enormemente arriscado", que é lícito falar com Christine Nüsslein-Volhard, ganhadora do Prêmio Nobel (2003, 10), de uma "resistência da natureza" e denominar o procedimento "em elevado grau contrário à natureza". Apesar disso, esse argumento pode vir acompanhado de um índice cronológico: arriscado de momento, talvez por muito tempo, mas não necessariamente "para toda a eternidade". Para o legislador atual, segue disso, porém, um claro mandamento, respaldado normativamente pelo juramento hipocrático: o direito ocasionalmente propagado à liberdade de reprodução ${ }^{2}$ tem um grau hierárquico claramente

2 Cf. procreative autonomy: Dworkin 1996, 104 s. 
inferior do que a responsabilidade pelo bem-estar previsivelmente (!) muito arriscado da futura criança. Enquanto esfera íntima, a reprodução exige do Estado um grau supremo de retração. Mas um experimento mental nos mostra que a retração total, a liberdade irrestrita de reprodução (reproductive freedom) seria absurda. Imaginemos pais que, por um cinismo praticamente incompreensível, se esforçassem e combinassem com outras pessoas, num assomo ainda potenciado de cinismo, dar à luz crianças que seriam, com elevadíssima probabilidade, deficientes gravíssimos: será que o Estado deveria continuar efetivamente passivo? Uma clonagem altamente arriscada não viola apenas os princípios de uma ética biomédica específica; já viola os princípios de uma ética geral dos experimentos com seres humanos. Se, no entanto, em virtude de um enorme avanço do conhecimento e da capacidade técnica, o risco da deficiência se torna "extremamente reduzido", eventualmente até de modo considerável menor do que na geração natural - embora todo o conhecimento biológico aponte na direção contrária -, a proibição da clonagem ver-se-ia privada de uma justificativa.

O terceiro argumento, mais uma vez uma hipótese factual, praticamente não vale em termos iguais para todas as culturas e épocas. Mas na nossa cultura, a vontade à particularidade respectivamente à diferença talvez seja a regra. Apesar disso, aparecem aqui dois pequenos pontos de interrogação. Por um lado, seres humanos geneticamente idênticos já aparecem na natureza, enquanto gêmeos homozigóticos, sem com isso perderem a oportunidade da particularidade, pois a individualidade humana não se deixa reduzir à dotação cromossômica. E mesmo no caso da concordância integral de genes, no caso dos gêmeos homozigóticos, não podemos inferir do conhecimento das características de um gêmeo prognósticos seguros sobre as do outro. Soma-se a isso, além de outras especificações menores fornecidas pelo citoplasma e pela gravidez, um leque colorido de fatores culturais e sociais. A evolução depende, sobretudo, dos dois lados: do indivíduo, de como ele se comporta com relação aos fatores parcialmente biológicos, parcialmente sociais, e das outras pessoas, de como os fatores e o que o indivíduo faz deles, são percebidos por elas.

Tudo faz crer que essa circunstância esvazia uma vez mais o potencial justificador de uma proibição absoluta. Mas ele esvazia também o lado oposto, a expectativa dos pais, pois eles não se importam com algo abstrato, como a prole geneticamente idêntica, mas muito mais concretamente com os filhos, especialmente bem-sucedidos quanto às suas habilidades manuais e sociais, intelectuais ou artísticas. Isso, porém, não pode nem de longe ser assegurado pela clonagem. Tampouco a clonagem pode garantir que no entorno social futuro as capacidades desejadas sejam avaliadas tão positivamente como hoje, e isso tanto em termos objetivos, pela sociedade, quanto também em termos subjetivos, nas representações que a criança faz da sua vida. Sobretudo a clonagem não assegura o objetivo mais importante de pais responsáveis, a ausência de narcisismo, da ambição pessoal ou do despotismo, mas a medida de auto-estima e respeito pela pessoa alheia, necessária para uma vida bem-sucedida. Por sua vez, o sonho da imortalidade é utópico, no sentido mais rigoroso do termo, pois o indivíduo doador "mor- 
re", enquanto não se necessita da clonagem para a alternativa, a sobrevivência na pessoa dos filhos. O mesmo vale para parceiros falecidos e para as crianças: eles são muito mais do que um programa genético, estando o 'mais' em princípio vedado à clonagem.

Kant não formulou apenas a elevada concepção da dignidade humana, mas apresentou também a proposta pragmática de um experimento mental: para examinar um juízo além da sua validade privada, deveríamos "pensar no lugar de qualquer outra pessoa" (Crítica do Juízo, § 40). Assim, quem pensa em clonar deve indagar se ele preferiria ter nascido como clone, quer dizer, não com a costumeira abertura (1) diante da sua auto-imagem, (2) diante do seu projeto de vida e futuro, (3) diante da sua auto-estima e (4) da estima, por parte de outras pessoas. Com relação a cada um desses quatro aspectos, essa pessoa ver-se-ia comprometida com um modelo com o qual dificilmente concordaria, por ele restringir gravemente as suas opções e oportunidades. Afinal de contas, os clones se distinguem de gêmeos homozigóticos, não na sua condição de duplicata genética, mas na origem da duplicata: neles, a origem está em uma instância anônima e isenta de responsabilidade, o acaso biológico; no caso dos gêmeos homozigóticos, ela está em uma pessoa que tem um nome e pode ser repreendida pelo gêmeo por ele ser uma cópia genética, quem sabe também pelo fato de ele ser uma cópia não-amada, por assim dizer a cópia falsa.

Como clone, não nos desenvolvemos na direção do gêmeo genético de modo cronologicamente paralelo, por conseqüência aberto, mas segundo um modelo, pelo qual eventualmente até seremos medidos de modo explícito: pagamos pela liberdade do outro com um elevado grau de falta de liberdade, embora esse outro disponha de um número suficiente de opções, de sorte que essa restrição da liberdade dificilmente pode ser justificada. Na formulação didaticamente exagerada de Habermas, de 1998, o clone é uma espécie de escravo, pois "pode transferir uma parte da responsabilidade, que de outro modo ele mesmo teria de suportar, para outras pessoas". De qualquer modo, a parcela dos genitores do clone assume o ônus de uma responsabilidade que, previsivelmente, não pode, logo não deve assumir.

A dignidade da pessoa é um princípio jurídico interculturalmente reconhecido, solenemente confirmado pelas Nações Unidas. Sem dúvida, uma criança produzida por clonagem é titular dessa dignidade, pois a dignidade compete ao ser humano, a partir da sua mera condição humana. As dúvidas apontam para outro problema, para a mera intrumentalização do clone em benefício de interesses alheios. Em contrapartida, a finalidade em si, contida na dignidade humana, exige a independência do arbítrio constrangedor dos outros, e isso é assegurado apenas pelo acaso biológico. Outro argumento contrário, a multiplicidade genética enquanto condição de sobrevivência da nossa espécie (Zimmer 1998), não se sustenta. Como existem aproximadamente 3 a 4 por mil de gêmeos homozigóticos, já temos agora, num mundo de quase 7 bilhões de pessoas, muitos milhões de duplicatas genéticas. Biologicamente considerados, mesmo milhares de clones importariam num aumento apenas insignificante dessas duplicatas (v. já Merkel 1998). Deve ser protegida, não a coletividade, a espécie, mas a instância que, em último lugar, é a única que conta, a pessoa individual, mas não isolada. 
São, porém, fundamentados dois outros argumentos contrários: por um lado, crianças clonadas constituem o primeiro estágio de crianças produzidas por meio de design; quer dizer, não são um estágio anterior à eugenia, mas já fazem parte de uma política eugênica, mesmo considerando a necessidade de delimitar uma "eugenia negativa", que procura eliminar certas doenças hereditárias, de uma eugenia positiva, que seleciona um patrimônio genético desejável. Por outro lado, não devemos subestimar o valor de relações familiares estáveis para o bem-estar de uma criança. Na clonagem, os riscos de tais relações, de qualquer modo já existentes, seriam mais uma vez reforçados: os pais poderiam tornar-se irmãos gêmeos dos seus filhos, os avós pais genéticos dos seus netos, as mães poderiam dar à luz um gêmeo genético de si mesmas. Decerto alguns dos riscos atuais são difíceis de evitar; mas a clonagem reprodutiva acabaria por aumentá-los levianamente, além disso de modo significativo. E como as nossas sociedades são comunidades solidárias, que, no caso emergencial, respondem pelas conseqüências, o balanço em termos de ética jurídica salta aos olhos: tanto do ponto de vista da proteção dos filhos quanto do ponto de vista da autoproteção da sociedade, mesmo uma clonagem com reduzidos riscos médicos somente poderá ser autorizada por um legislador irresponsável.

\section{Digressão: doação, não propriedade}

Na sua conferência, Michael Sandel lembra com razão que crianças devem ser tratadas "como doação, não propriedade". Ele vê nesse ponto de vista uma alternativa à "linguagem" dos direitos fundamentais e humanos e continua a sua argumentação afirmando que já agora o "seu" critério de uma relação adequada com os filhos é violado, com freqüência e de múltiplos modos. Duas perguntas de esclarecimento impõem-se aqui:

Em primeiro lugar, devemos perguntar se qualquer violação, mesmo a mais ínfima, é tão relevante do ponto de vista jurídico que primeiro o Legislativo, depois, no âmbito da legislação, o Executivo e, no caso de um litígio, o Judiciário podem e talvez até devam interferir? A resposta provavelmente será semelhante à dada com referência à reprodução: a educação de filhos é um espaço de intimidade, no qual o ordenamento jurídico só pode interferir no caso extremo, e.g. no caso do abandono ou da ocorrência de violência física, eventualmente também psíquica. Se pais ambiciosos "adestrarem" seus filhos demasiado cedo, e com demasiada intensidade, para que obtenham rendimentos elevados, isso deveria motivar menos medidas coercitivas, por parte do ordenamento jurídico, do que o protesto de parentes e amigos, também da opinião pública. Como nem toda infração tem relevância jurídica, necessitamos de um critério delimitador. E, para tal fim, se recomenda a "linguagem", com relação à qual Sandel demonstra ceticismo: a linguagem dos direitos fundamentais e humanos, inclusos os direitos fundamentais das crianças. Isso não impede que se critique adicionalmente, com dureza, como já insinuamos, na forma de uma crítica social, aquele pensamento centrado na idéia da propriedade de crianças que ainda não permite a intervenção 
do ordenamento jurídico dotado de competências coercitivas, pois a ética jurídica não coincide com todo o âmbito da ética social, mas cobre apenas um núcleo do qual não se pode abrir mão.

A segunda pergunta de esclarecimento tem por objeto a justificação da ética, "doação, não propriedade". Com vistas à pergunta por que crianças não podem ser propriedade, oferece-se novamente a linguagem da dignidade fundamental e da dignidade da pessoa. De qualquer modo, a proibição da instrumentalização da dignidade humana contém a proibição de usar qualquer pessoa, conseqüentemente também crianças, apenas para fins alheios, isto é, de abusar de crianças.

\section{4 “Clonagem terapêutica" ou "investigativa"?}

Muitas objeções caem por terra na segunda modalidade da clonagem. No lugar delas, as dificuldades já principiam na semântica: deveríamos falar de "clonagem terapêutica" ou, preferencialmente, de "clonagem investigativa" ou, ainda mais preferencialmente, de um aumento direcionado de um "conjunto de células totipotentes"?

A expressão "clonagem terapêutica" contém uma promessa de cura com a qual os pesquisadores se podem comprometer pessoalmente, que, além disso, lhes facilita o apoio da sociedade, mas que não cobre a pesquisa atual. Ela designa uma esperança distante, mas nem aproximativamente a realidade. Quem reprime isso sucumbe a uma falácia humanitarista, pois as pesquisas ocupam-se (a) dos preparativos para (b) novas possibilidades de (c) uma terapia concreta; são tão-somente preliminares de preliminares de uma ajuda futura (Höffe 2003, 2. ed., 44 s., nessa publicação a quarta espécie de falácias). Trata-se, com efeito, de preparativos, pois não tanto a pesquisa de base espera aqui novas descobertas como uma pesquisa orientada segundo a ajuda médica, que, com células embrionárias, pretende, em última instância, tornar curáveis doenças como diabetes infantil, o mal de Parkinson e a esclerose múltipla. Em oposição a isso, as expressões "multiplicação de células" e "conjunto de células" preservam a soberania argumentativa da Biologia, pois evocam uma ciência natural pura, sem ensejarem quaisquer perguntas de esclarecimento pela dimensão jurídico-moral, temidas por alguns. Não devemos esquecer que embriões humanos fixam limites à pesquisa do direito vigente, da Lei de Proteção dos Embriões, embora com boas razões. É vedado matar vida humana - também para fins de pesquisa ou terapia. Por isso a expressão "clonagem terapêutica" pretende demais, enquanto a expressão "aumento direcionado de células" diz demasiado pouco. Assim sendo, recomenda-se seguir a Comissão Kass e falar de "clonagem para fins biomédicos", eventualmente também de "clonagem para a pesquisa terapêutica", mas na forma abreviada de "clonagem investigativa".

$\mathrm{O}$ que distingue essa clonagem da clonagem reprodutiva, com a pergunta adicional: será que se trata de fatores que exoneram suficientemente, de modo que a pesquisa se torna jurídica e eticamente isenta de problemas? A clonagem reprodutiva persegue fins privados, nem sempre respeitáveis, ao passo que a clonagem investigativa serve a um interesse claramente público, no longo prazo humanitário e médico. Ela serve ao progresso do conhecimento aplicável, que tem boas chances 
de cumprir tarefas médicas, no longo prazo. Mas o próprio procedimento é, num primeiro momento, idêntico, de modo que nos devemos perguntar se a intenção altera a ação de modo a repolarizar a dimensão axiológica no plano jurídico-moral: do negativo na direção do positivo, ao menos na direção do neutro.

Nesse tocante, a discussão atual em torno da Ética e do Direito não chegou a um consenso. Também na Comissão Kass as duas posições concorrentes impedem a elaboração de uma posição conjunta. Um lado, o da aceitação utilitarista, argumenta em seis passos: considera, em primeiro lugar, embriões em estado inicial dignos de proteção, embora não irrestrita. Por isso ela admite, em segundo lugar, uma ponderação utilitarista de bens jurídicos. Em terceiro lugar, ela contesta uma intenção destrutiva (not created for destruction) e ressalta, em quarto lugar, um fim hierarquicamente elevado, o serviço prestado à vida e à medicina, enquanto ela o qualifique, em quinto lugar, honestamente, embora de modo quase escondido, como apenas possível (may come from it). Disso ela infere, em sexto lugar, que o eventual grande bem tem um peso superior ao das objeções morais. Em contrapartida, a outra posição, muitas vezes denominada deontológica, vê na clonagem investigativa uma injustiça moral, pois ela exploraria e destruiria a vida humana em vias de formação, fato condenável, mesmo no caso de boas intenções.

Três perguntas são importantes para uma avaliação ética. Nenhuma delas se interessa efetivamente pela oposição de utilitarismo e deontologia, de modo que a apreciada estratégia de exoneração perde a sua razão de ser: se os representantes da filosofia moral não conseguem chegar a um consenso aqui, a decisão em favor da deontologia ou do utilitarismo fica a critério de cada um.

Com vistas à primeira pergunta, pela relevância do fim, deve-se distinguir entre um fim interno e outro externo à ação. No primeiro caso, o fim é essencial à ação ou constitutivo; no segundo, ele não é essencial nem constitutivo. Se dou dinheiro a uma pessoa, é de essencial importância saber se com isso estou remunerando o trabalho prestado ou se quero apenas induzi-la a violar um dever ex officio. Pago no primeiro, suborno no segundo caso. Em ambos, o fim integra a definição da própria ação; é interno a ela ou a constitui, sem ele a ação remanesceria subdeterminada. Diferentemente é a situação do (outro) fim, que quero atingir mediante o suborno. Ele pode ser bom ou ruim, mas é externo à ação e não altera o fato de que se trata, em primeiro lugar, de um suborno e que este é, em segundo lugar, condenável em termos éticos bem como jurídicos. Similarmente uma inverdade consciente, uma mentira, é condenável, ainda que seja tratada com indulgência quando afirmada em situação emergencial ("mentira forçada"). Assim a resposta à primeira pergunta é fácil: ambas, a reprodução e a pesquisa, não são fins constitutivos da ação, mas externos ao processo da clonagem. Mesmo a um clone produzido para a pesquisa genuinamente terapêutica não se pode negar a qualidade de ser, no caso de óvulos humanos fecundados, o estágio inicial de um embrião humano. Conseqüentemente, o fim não pode repolarizar aqui a dimensão do valor moral, mas pleitear a indulgência na realização de uma clonagem efetivamente terapêutica. Assim o fim humanitário não exonera a clonagem investigativa, ao menos não suficientemente. 
As coisas seriam distintas, se a clonagem investigativa - eis a segunda pergunta - se distinguisse da clonagem reprodutiva, independentemente do seu fim exterior, quer dizer, no plano interno do clone? Aqui a resposta não é tão fácil, pois há vários itens não-controvertidos, embora um remanesça controvertido. Conclusa a fecundação, não há controvérsias quanto à existência de um ser vivo, a saber, de um ser que vive a partir de si, que se organiza e replica em conformidade com o seu próprio genoma individual. Igualmente não há controvérsias com referência ao fato de não se tratar de um ser subumano, pois o ser em evolução pertence à nossa espécie e a nenhuma outra, independentemente de ser gerado in vitro ou in vivo. Por fim, também não há controvérsias quanto ao fato de que, no âmbito de uma evolução complexa, a nidação no útero é importante, pois ela concede alimentação e proteção, provavelmente também envia sinais de ativação, embora isso, pelo que sei, ainda não esteja cabalmente comprovado. As controvérsias surgem apenas no tocante à relevância jurídica.

As objeções contra uma valorização excessiva da evolução principiam no fato biológico de que a clonagem reprodutiva e investigativa resultam no mesmo produto intermediário, por sua vez aberto a um implante num útero, quer dizer, na utilização para a clonagem reprodutiva, o que reforça a nossa descoberta de que a finalidade da clonagem não é constitutiva. Uma segunda objeção parte do aspecto jurídico, da dignidade de proteção, característica para o ser humano. Para ela é de essencial importância que ela não depende de um determinado rendimento ou de uma qualidade nem de uma atribuição por terceiros. Como digna de proteção, a vida humana já vale pelo simples fato de ser humana. Nesse sentido, a clonagem investigativa se afigura até mais problemática, pois gera embriões humanos, com o objetivo de lhes negar, depois de algum tempo, a possibilidade do desenvolvimento ulterior. Com isso a vida humana é claramente instrumentalizada para terceiros, o que causa dificuldades de justificação pelo fato de nossa tradição jurídica admitir uma ponderação de bens somente no caso excepcional, quando uma vida se opõe a outra.

De qualquer modo, a terceira e decisiva pergunta é a seguinte: qual é o status do produto intermediário ainda aberto para a reprodução e investigação? A mera pergunta confirma que o pomo da discórdia está localizado fora da diferença entre as éticas utilitarista e deontológica, no status jurídico do conjunto de células humanas. Se ele é, desde o princípio, uma vida humana, a ponderação utilitarista de bens não assenta em nenhum direito, diferentemente do caso contrário. Quando, portanto, a vida humana começa a ser digna de proteção?

Os defensores da clonagem investigativa concedem a existência de um valor de proteção, embora apenas relativo. A parte contrária contesta com o argumento de que o que alguns querem minimizar como "mero amontoado de células" contém, desde o princípio, enquanto óvulo fecundado com o duplo conjunto de cromossomos, o programa integral da vida para o desenvolvimento de um ser humano. À diferença de um bulbo ou dos ovos postos por peixes, sapos e pássa- 
ros, os mamíferos, e também o ser humano, necessitam de um entorno exigente, do útero, mas o programa de vida é inequivocamente de natureza humana, e ele já iniciou de forma igualmente inequívoca o seu desenvolvimento. Ele não necessita de aperfeiçoamento ulterior, mas transcorre nesse sentido num continuum: com fundamento num automonitoramento, não em conformidade com leis ou programas alheios, mas sujeito à sua própria lei e ao seu próprio programa. Como a relativização feita, e.g., pelo oponente, com referência às operações do útero, somente transcorre no âmbito dessa continuidade básica, a clonagem investigativa permanece em última instância problemática, do ponto de vista ético e jurídico. As três instâncias: o nosso ordenamento jurídico, o juramento hipocrático e a filosofia moral distinguem entre uma moral jurídica, cujo reconhecimento os homens se devem reciprocamente, e as operações adicionais voluntárias de uma moral fundamentada na virtude. E elas complementam que, em nome do mandamento da ajuda (ambientado na moral da virtude), não é lícito matar qualquer vida humana. Abstraindo da legítima defesa, é vedado até $\mathrm{o}$ dano à vida.

Felizmente estão aparecendo mais recentemente possibilidades da reprogramação que evitam o caminho pelo embrião humano, conseqüentemente 'desempregam' as correspondentes objeções. Por essa razão, e também pelo fato de o caminho de células-tronco embrionárias até terapias eficazes ainda ser muito longo, adicionalmente pelo fato de mesmo especialistas serem céticos quanto ao potencial terapêutico, deveríamos abandonar a fixação nos procedimentos adotados até agora e liberar a criatividade científica, a sede de saber inicialmente mencionada, para métodos não-problemáticos, do ponto de vista ético-jurídico.

\section{Referências}

Allensbach 2003: Die Allensbacher Berufsprestige-Skala 2003 (Allensbacher Berichte 2003, n. 7)

CAMUS, A. Le premier homme. Paris, 1994; tradução para o alemão sob o título Der erste Mensch. Reinbek bei Hamburg, 1997.

Council $=$ The President's Council on Bioethics 2002: Human Cloning and Human Dignity. An Ethical Inquiry. Washington, D.C.

DAMSCHEN, G.; D. SCHÖNECKER (Ed.) 2003: Der moralische Status menschlicher Embryonen. Pro und contra Spezies-, Kontinuums-, Identitäts- und Potentialitätsargument. Berlim; Nova Iorque.

Dossier 2003: Klonen beim Menschen, editado pelo Deutsches Referenzzentrum für Ethik in den Biowissenschaften (DRZE), Bonn.

DWORKIN, Freedom's Law. Oxford, 1996.

FLETCHER, J. The Ethics of Genetic Control. Ending Reproductive Roulette. Nova Iorque, 1974.

Forum Diderot 1999: Faut-il vraiment cloner l'homme. Paris.

HABERMAS, J. Sklavenherrschaft der Gene. Moralische Grenzen des Fortschritts, in: Süddeutsche Zeitung, 17./18.1.1998, p. 13.

HÖFFE, O. (Ed.). Lexikon der Ethik. Munique, ${ }^{6} 2002$. 
HÖFFE, O. Medizin ohne Ethik? Frankfurt/M. ${ }^{2} 2003$.

JAENISCH, R.; I. WILMUT: Don't Clone Humans! in: Science 291, 2552, 2002.

JONAS, H. Biological Engineering - A Preview, in Id.: Philosophical Essays. From ancient creed to technological man. Englewood Cliffs, NJ, 141-167, 1972.

KANT, I. Kritik der Urteilskraft, in: Gesammelte Schriften, ed. Königlich Preußische Akademie der Wissenschaften,. Berlim 1902 s., V, 165-485.

KIRCHHOF, HONNEFELDER, ISENSEE, HÖFFE: Gentechnik und Menschenwürde. Colônia, 2002.

MCLAREN, A. (Ed.). Cloning, Council of Europe. Estrasburgo, 2002.

MERKEL. R. Die Fürsorge maskiert den Egoismus, in: Die Zeit, 5.3.1998, 37-38.

NÜSSLEIN-VOLHARD, C. Wann ist der Mensch ein Mensch? Embryologie und Gentechnik im 19. und 20. Jahrhundert. Heidelberg, 2003.

Reader 2003: Klonen in biomedizinischer Forschung und Reproduktion. Wisssenschaftliche Aspekte ethische, rechtliche und gesellschaftliche Grenzen Ed. Deutsches Referenzzentrum für Ethik in den Biowissenschaften (DRZE). Bonn.

SCHATTEN, G. et al. 2003: Molecular Correlates of Primate Nuclear Transfer Failures, in: Science 300, 297.

ZIMMER, D. E. 1998: Eineiige Zwillinge sollen Zufall bleiben, in: Die Zeit, 12.2. 